peculiar make (constituted as a hinge, to allow equable tight. ening of the wires by three screws), the two clamps were brought as near together as possible (the vulva being between them ), and secured to the wires in that position. Four or five superficial sutures of wire were now applied, to bring the an. terior edges of the wound together; and the vagina was well syringed out. A very considerable amount of hæmorrhage occurred during the operation, so as to necessitate the ligature of one or two small vessels. A catheter was now passed, and left in the bladder, attached to a long India-rubber tube. A suppository of morphia was given at night, with from half a grain to a grain of crude opium by the mouth.

Feb. 28th. The catheter, causing some irritation, was removed, and ordered to be passed three times a day.

March 1st. There is considerable discharge. She sleeps well, and does not complain of pain. The vagina was ordered to be washed out with lukewarm water. The deeper sutures were removed to-day. There was some amount of bleeding. The urine passed is very thick. The union is complete.

The irritation of the bladder lasted some days, but ultimately gave way. The superficial sutures were removed about the eighth day after the operation. She left the Hospital on April 3rd, with a good firm perinæum, wearing a $T$ bandage as a precautionary measure; the womb being completely kept up.

CASE II. M. A. D., aged 21, a servant, was admitted De cember 15th, 1858, under the care of Dr. Routh. She is of a fair complexion, and generally healthy. She had rheumatic fever three years ago, and was at that time very ill for about six months. There were no cardiac symptoms to be traced. She was married four years ago, and had two children born alive. The first child died at eight months old, from convulsions. The second was a six months child, and died nine days after birth, also in convulsions; it barely took the breast, and had to be fed with a spoon. This second confinement took place in the workhouse. It began at 4 , and terminated at between 7 and 8 P.Mr. She was not aware that she had been torn; but it gave her great pain and bearing down, when she got up to walk, on the eleventh day. The womb was at this time quite out, so that she could both see and feel it; and, two or three days subsequently, it protruded as completely as it does now. She did not mention this circumstance to the medical man. It has continued down ever since-i.e., about a twelvemonth-giving her great uneasiness and occasional pain, and difficulty in walking; but latterly she has suffered less in these respects. She has been in place three months from the date of her confinement. The catamenia first began at thirteen years old. She has been regular ever since, though the secretion has been scanty, and lasts four days upon her. No leucorrhœa has been present, except when she has been walking about and working.

There is a pyriform shaped tumour, of about the size of a large pear, protruding between her legs. The apex of the cone constitutes the os uteri, which is large and patent, with ul. cerated portions of mucous membrane round it, and here and there with thickened patches of epithelium. The superior wall consists of the bladder, completely extraverted with the uterus and vagina. The posterior wall is made up in the same way by the protruded rectum. A catheter, to penetrate the bladder, has to be directed anteriorly, following the curve of the protruded uterus. She experiences considerable difficulty in passing urine. When the bladder is full, the protruded parts are considerably enlarged. There is scarcely any perinæum. The prolapsus can be readily returned.

Dec. 30th. The patient being placed under the influence of chloroform, the urine drawn off, and the prolapsed parts re. duced, about one-third of an inch of the external skin, and the mucous membrane of the vagina, extending an inch and a half up the lower two-thirds of the vagina, were dissected off. The deep sutures, consisting of double silver threads, were put in by the ordinary bent needles; the whole secured by two perforated pieces of whalebone, one on each side; and kept in position and tightened by perforated shot, and by about six or seven superficial silver sutures. The catheter was placed in the bladder with a long India-rubber tube. There was a considerable amount of hæmorrhage during the operation. Cold water dressing was applied.

Dec. 31st. Three morphine suppositories have been used in the course of the night. She has not slept, but has been quiet. Tongue rather dry; pulse 84. No further hæmorrhage has occurred. The vagina was syringed out.

Jan. 1st, 1859. She complains of some pain, but has slept all night. An effervescent mixture was ordered, and a glass of wine.
Jan. 2nd. The deep sutures were removed. Union complete. One suppository only was ordered to be used every night. Three ounces of wine were given. This evening, an attack of rigors, followed by copious perspiration, occurred. Tongue cleaning; pulse 84 .

Jan. 3rd. The wound looks healthy. There is no sloughing about the position of the deep sutures. The vagina was washed out. Three glasses of wine were ordered daily. Chlorate of potass lotion was directed to be applied externally.

From this time she continued to improve. The catheter was removed on January 4th. On January 5th, the superficial sutures were removed. A small superficial slough at the upper part of the wound made its appearance, but yielded to poultices and generous diet. The parts were completely healed by the 15th. She left the Hospital cured, Jan. 26th, 1859.

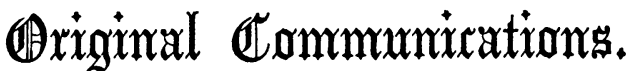

\section{STATISTICS OF ONE THOUSAND CASES IN OBSTETRICS.}

By I. Harrinson, Esq., F.R.C.S., Fellow of the Obstetrical Society.

[Read before the Reading Pathological Society, August 17th, 1859.] [Continued from page 871.]

Complicated Labour.-Thirty.one cases.

The cases are thus arranged-

Twins .......... 10 | Prolapsus of cord.... 3

Hæmorrhage $\ldots \ldots$.... 11 Tumour $\ldots \ldots \ldots \ldots$..... 2

Prolapsus of bladder $\quad 2$ Hydrocephalus ........ I

Convulsions $\ldots \ldots, 2$

Twins.-Ten cases.

\begin{tabular}{|c|c|c|c|c|c|c|}
\hline & $\begin{array}{c}\text { Age of } \\
\text { mother. }\end{array}$ & $\begin{array}{l}\text { No. of } \\
\text { child. }\end{array}$ & $\begin{array}{l}\text { Durntion } \\
\text { in hours. }\end{array}$ & Sex. & Labour. & $\begin{array}{l}\text { State of } \\
\text { child. }\end{array}$ \\
\hline & 35 & 4 & 2 & F. & Natural. & Alive. \\
\hline 2 & & & 2.30 & F. & $\mathrm{Na}$ & - \\
\hline 3 & 33 & 3 & 11 & F. & Bre & - \\
\hline 4 & & .. & 11.45 & M. & Breech. & - \\
\hline 5 & 42 & 8 & 3 & $\mathrm{~F}$. & Foot \& knee. & - \\
\hline 6 & & ・ & 3.30 & M. & Foot. & 一 \\
\hline 7 & 28 & 2 & 3.30 & F. & Breech. & 一 \\
\hline 8 & 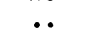 & ・・ & 4 & F. & Feet. & - \\
\hline $\boldsymbol{\theta}$ & 31 & 4 & 3 & M. & Cord \& feet. & Deac \\
\hline$\{10$ & $\cdots$ & ・. & 3.15 & F. & Feet. & Aliv \\
\hline j11 & 33 & 7 & & F. & Natural. & - \\
\hline$\{12$ & 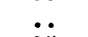 & $\cdots$ & 7.15 & M. & Breech. & - \\
\hline$\{13$ & 25 & 3 & & $\mathrm{~F}$. & ral. & - \\
\hline$\{14$ & $\cdots$ & $\cdots$ & 4.15 & M. & Natural. & - \\
\hline$\{1$ & 36 & 2 & 8.15 & F. & Natural. & - \\
\hline$\{1$ & & $\cdots$ & 8.45 & F. & Both knees. & - \\
\hline 17 & 37 & 6 & 6 & F. & Natural. & - \\
\hline 11 & & • & 6.30 & F. & Breech. & - \\
\hline - & 32 & 1 & & F. & Craniotomy. & Dea \\
\hline & & & & F. & Forceps. & \\
\hline
\end{tabular}

The ages of the mothers in the twin cases were-

Under 25 years .... $0 \mid 35$ to $40 \ldots \ldots \ldots \ldots . .3$

25 to $30 \ldots \ldots \ldots \ldots .2) \quad 40$ to $45 \ldots \ldots \ldots \ldots, 1$

30 to $35 \ldots \ldots \ldots \ldots, 4.6 .4$

Seven out of ten were between 30 and 40 years of age. The mean age was 33 years.

According to the number of pregnancies, there were-

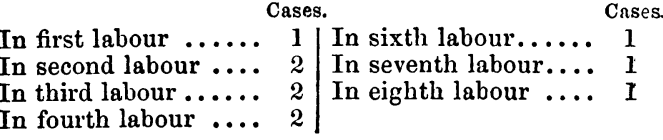

The mean duration of labour was ten hours; but, deducting one remarkable case, the mean duration is little more than five hours.

Of the presentations, three natural in both; one breech in each; in two, the first child presented the head, the second the breech; in one case, the first presented the head, the second 
the knees ; in two cases, the foot or feet were present, one with a knee and one with cord; and in one instance, the first child presented the breech, and the second the feet.

Of the twenty children, seventeen were alive and three dead. Of the dead, one was dead before I arrived; on one craniotomy was performed; and to one (dead) the forceps was applied.

There were five males and fifteen females. In five cases both twins were females: and in five others, one was male and one female.

$$
\text { Hamorrhage.-Eleven cases. }
$$

\begin{tabular}{|c|c|c|c|c|c|c|c|c|}
\hline 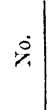 & Age. & $\mid \begin{array}{c}\text { No. } \\
\text { of } \\
\text { child. }\end{array}$ & 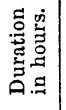 & Sex. & Period. & $\begin{array}{c}\text { State } \\
\text { of } \\
\text { child. }\end{array}$ & $\begin{array}{c}\text { Presen. } \\
\text { tation. }\end{array}$ & hage. \\
\hline 1 & 26 & 4 & 2 & F. & Full. & Alive. & Nat. & $p$ \\
\hline 2 & 43 & 5 & 3 & F. & $\begin{array}{c}7 \\
\operatorname{mos}\end{array}$ & Dead. & Nat. & $\begin{array}{l}\text { led acci- } \\
\text { l. }\end{array}$ \\
\hline 3 & 19 & 1 & 6 & M. & Full. & Ali & $\mathrm{Na}$ & acenta. \\
\hline 4 & 37 & 7 & 16 & $\mathrm{~F}$ & 7 & De & $\mathrm{N}$ & $\begin{array}{l}\text { al pre- } \\
\text { tion near- }\end{array}$ \\
\hline 5 & 36 & 4 & 2 & M. & Full. & Dead. & Feet. & $\begin{array}{r}\text { Befo } \\
\text { pl }\end{array}$ \\
\hline 6 & 33 & 9 & 4 & F. & $\begin{array}{c}7 \\
\text { mos. }\end{array}$ & Alive. & Nat. & $\begin{array}{r}\text { Part } \\
\text { pr }\end{array}$ \\
\hline 7 & 35 & 3 & 12 & M. & $\begin{array}{l}7 \frac{1}{2} \\
\text { mos. }\end{array}$ & Dead. & Nat. & $\begin{array}{l}\text { d acci- } \\
\text {; fatal. }\end{array}$ \\
\hline 8 & 38 & 7 & 8 & F. & $\begin{array}{c}7 \\
\text { mos. }\end{array}$ & Dead. & Nat. & $\begin{array}{l}\text { Concealed acci- } \\
\text { dental ; fatal. }\end{array}$ \\
\hline 9 & 36 & 7 & 3 & M. & Full & Alive. & Nat. & $\begin{array}{l}\text { led acci- } \\
\text { al. }\end{array}$ \\
\hline 10 & 39 & 7 & 27 & M. & ull. & Alive. & Nat. & lacental \\
\hline 1 & 31 & 2 & 7 & F. & Full. & Dead. & Nat. & After placenta. \\
\hline
\end{tabular}

Arranging the cases of hæmorrhage according to the number of pregnancies, there were-

$$
\text { Cases. Cases. }
$$

With first child .... $1 \mid$ With fifth child .... 1

With second child .. 1 1 With seventh child .. 4

With third child .... 1 With ninth child .... I

With fourth child $\ldots . .2$

The mean age of the mother was 34 years. The mean duration of labour was eight hours. Of the children, six were females and five males. Six were delivered at the full period; four at seven months; and one at seven months and a half. Five were alive and six dead. Of the live ones, one was born at seven months, and lived four days. Of the dead ones, two were born at the full period.

The varieties of hæmorrhage were:-before and with placenta, 3 ; concealed accidental, 4 ; placental presentations, 3 ; and after placenta, 1 .

I must limit myself to a few observations on one form of hæmorrhage; viz., the internal. The table contains a sum. mary of the rest. It will be remembered that in 1852 , I read before this Society a case of a peculiar form of uterine hæmorrhage, which was unique, as far as my practice was concerned, and which had not then occurred to any other member of the Society. It was only incidentally named-not described-by some of the authors then enumerated. The case was pub. lished in the Association MEdicar Journar for 1853, and excited some interest. Professor Murphy kindly directed my attention to his Lectures, where this form of hæmorrhage was more particularly mentioned. In Guy's Hospital Reports for 1856 , Dr. Oldham has written a very good paper on this subject, under the appropriate title of "Concealed Accidental Uterine Hæmorrhage", and has confirmed the expression of its rarity and its danger. Some well marked cases have been since published in the various journals.

In the latter part of the year 1852, I met with a second case, also fatal. Two slighter cases have also occurred: one in 1840 , and the other in 1853 .

The table does not include those rather frequent cases where hæmorrhage occurs occasionally during pregnaney without any obvious cause.

$$
\text { Convulsions.-Two cases. }
$$

1. Aged 31 ; married ; first child ; duration of labour, seven hours ; female; presentation natural; from fright treated by bleeding; recovery.
2. Aged 31 ; single; first child; duration of labour, eight hours; male; presentation natural; albuminous urine; treated by bleeding; death.

In both, the children were born alive.

That there should be only two cases of convulsions, is worthy of some notice. One occurred from fright, from the napkins at the fire becoming ignited during labour, and was readily controlled. The other was a case of great œdema, with albuminous urine, seen for the first time only the day before convulsions occurred, and before any curative measures were employed. I refer to those conditions of which albuminous urine forms so significant a sign. In other casesand the signs and symptoms are usually amply sufficient for their detection-preliminary preventive treatment was success. fully employed. I entirely dissent from Dr. Copeman, who has little faith in preventive means. My friends, Mr. Workman and Mr. Walford, have permitted me to add their testimony of the value of anticipatory treatment.

Of course, it must not be taken for granted that where there is odema, there must necessarily be found albuminous urine. Extreme œdema is often present without albuminous urine.

With the second case, above referred to as my text, I read a long paper before this Society, in which I endeavoured to show-and fancied I succeeded in so doing-that a more comprehensive view should be taken of puerperal convulsions, mania, and the various forms of puerperal fever, etc., as the same cause, or combination of causes, might and did eventuate in the production, indifferently, of one or the other disease, according to the idiosyncrasy of the patient.

Prolapsus of the Cord.-Six cases.

This class includes all the cases where prolapsus of the cord occurred, though some belong to other classes. Amid the variety of complication, it will be seen that only one

\begin{tabular}{|c|c|c|c|c|c|c|}
\hline No. & Age. & $\begin{array}{l}\text { No. of } \\
\text { child. }\end{array}$ & $\begin{array}{l}\text { Dura- } \\
\text { tion of } \\
\text { labour. }\end{array}$ & Sex. & $\begin{array}{l}\text { Nature of } \\
\text { prolapsus. }\end{array}$ & Result. \\
\hline 1 & 42 & 5 & $\begin{array}{c}\text { Hours. } \\
15\end{array}$ & M. & Cord and head. & Child dead. \\
\hline 2 & 25 & 3 & 4 & M. & Cord with neck. & Child alive. \\
\hline 3 & 34 & 10 & 36 & M. & $\begin{array}{l}\text { Cord with head } \\
\text { and hand ; }\end{array}$ & Child dead. \\
\hline 4 & 31 & 4 & 3 & M. & $\begin{array}{l}\text { Cord and feet; } \\
\text { lst of twins. }\end{array}$ & $\begin{array}{l}\text { Child dead } \\
\text { before I ar- } \\
\text { rived. }\end{array}$ \\
\hline 5 & 29 & 3 & $\tau$ & F. & $\begin{array}{l}\text { Cord and feet; } \\
\text { induced la- } \\
\text { bour. }\end{array}$ & $\begin{array}{c}\text { Child lived } \\
\text { some min- } \\
\text { utes. }\end{array}$ \\
\hline 6 & 37 & 1 & 5 & F. & Cord and arm. & Child dead. \\
\hline
\end{tabular}
child lived. The class must be considered a very dangerous one.

Prolapsus of the Bladder occurred in two cases, which pre sented nothing remarkable. The bladder was not in the way.

Tumour. There were two cases of tumour.

1. Mother, aged 28; fourth child ; duration of labour, twelve hours; child, a female; labour natural; child alive. There was a tumour of the left ovary. I did not find it in subsequent labours.

2. Mother, aged 32; first child ; duration of labour, three days ; child, a male; breech presentation. A solid tumour filled up the hollow of the sacrum, and extended into the cavity of the pelvis. Premature labour was induced at seven months with the second child; at eight months with the third child. The tumour was much the same. After this it disappeared; and the fourth child was allowed to go to the full period.

Hydrocephalus occurred in one case. The mother was aged 30 ; first child ; duration of labour, 51 hours; child, a male head presentation; perforation; two or three pints of fluid removed. The mother recovered.

Retroversion of Uterus was found in one case. It occurred in a woman, aged 39 , with her first; it happened when she was advanced between three and four months. She was kept on her elbows and knees and the prope position for a fortnight during which time it recurred three or four times. After this, it did not return. She was safely delivered at eight months the child was alive. 
Instrumental Labours.-Twenty cases.

\begin{tabular}{|c|c|c|c|c|c|c|c|c|c|c|}
\hline No. & Age. & $\begin{array}{l}\text { No. of } \\
\text { child. }\end{array}$ & Hours. & Sex. & Operation. & State of child. & $\begin{array}{l}\text { Cause of } \\
\text { obstruction. }\end{array}$ & Presentation. & $\begin{array}{l}\text { Period of } \\
\text { pregnancy. }\end{array}$ & $\begin{array}{l}\text { Result to } \\
\text { mother. }\end{array}$ \\
\hline 1 & 38 & 1 & 28 & M. & Forceps & Alive & & Head & Full & Recovery \\
\hline 2 & 23 & 1 & 15 & M. & Forceps & Alive & Loaded bowel & Head & Full & Do. \\
\hline 3 & 37 & 1 & 26 & F. & Forceps & Alive & & Head & Full & Do. \\
\hline 4 & 42 & 7 & 27 & M. & Forceps & Alive & & Head & Full & Do. \\
\hline 5 & 30 & 1 & 51 & M. & Perforator & Died in birth & Hydrocephalus & Head & Full & Do. \\
\hline 6 & 32 & 2 & 3 & F. & Induced & Alive & Tumour & Feet \& cord & 7 months & Do. \\
\hline 7 & 27 & $\tilde{l}$ & 4 days & F. & Forceps & Alive & & Head & Full & Do. \\
\hline 8 & 34 & 3 & $4 \frac{1}{2}$ & $\mathrm{~F}$. & Induced & Died in birth & Tumour & Breech & 8 months & Do. \\
\hline 9 & 24 & 1 & 24 & $\mathrm{~F}$. & Forceps & Alive & & Head & Full & Do. \\
\hline 10 & 30 & $\overline{2}$ & 16 & $\mathrm{~F}$. & Forceps & Alive & & Head & Full & Do. \\
\hline ]1 & 45 & 11 & 7 & F. & Perforator & Died in birth & Deformity of brim & Head & Full & Do. \\
\hline 12 & 42 & 2 & 20 & M. & Forceps & Alive & & Head & Full & Do. \\
\hline 13 & 35 & l & 12 & M. & Perforator & Died in birth & Deep perineum & Head & 7 months & Do. \\
\hline 14 & 31 & 1 & 51 & $\mathrm{~F}$. & Forceps & Alive & & Head & Full & Do. \\
\hline 15 & 24 & ] & 10 & M. & Forceps & Dead and putrid & & Head & Full & Do. \\
\hline 16 & $\tilde{21}$ & 1 & 24 & $\mathrm{~F}$. & Perforator & Died in birth & Deformed pelvis & Head & Full & Do. \\
\hline 17 & 40 & 4 & 12 & M. & Perforator & Dead some days & Deformed pelvis & Head & Full & Do. \\
\hline 18 & 35 & 3 & 12 & M. & Perforator & Died in birth & Concealed hæ- & Head & 7 months & Death \\
\hline 19 & 32 & 1 & 48 & F. & Perforator & Dead some days & & Head & Full & Recovery \\
\hline 20 & 32 & 1 & 50 & F. & Forceps & Dead some days & & Head & Full & Do. \\
\hline
\end{tabular}

Omitting tro "induced", there remain eleven forceps and seven perforator cases.

Analysing this table, we have the following results:-

Forceps cases :

Age: 20 to 30 -

" $\quad 40$ to 40 to 45 .

Pregnancy : First

Second$$
"
$$

Seventh

Mean age of patients

Duration of labour: Shortest

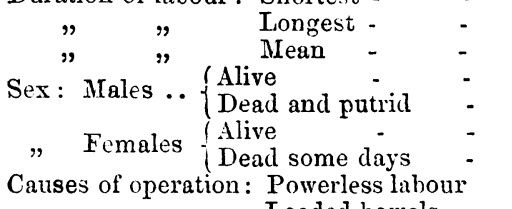

$$
" \text { Loaded bowels }
$$

Perforator cases :

Putrid child, etc.

Age : 20 to 30

, 30 to 40

, 40 to 45

Pregnancy : First

$$
\begin{array}{ll}
\text { ", } & \text { Third } \\
, & \text { Fourth } \\
, & \text { Eleventh }
\end{array}
$$

Mean age of patient

Duration of labour: Shortest

\section{Longest}

$$
" \quad " \quad \text { Monge }
$$

Sex: Males ... Died in birth

.. $\left\{\begin{array}{l}\text { Dead before birth } \\ \text { Died in birth }\end{array}\right.$

, Females $\left\{\begin{array}{l}\text { Died in birth } \\ \text { Dead before birth }\end{array}\right.$

Causes of operation: Hydrocephalus

$$
\begin{aligned}
& \text { Concealed hæmorrhage } \\
& \text { Deformity of pelvis } \\
& \text { Deep perinæum (child) } \\
& \text { dead-seven months) } \\
& \text { Child dead-lst of twins }
\end{aligned}
$$

4 cases.

5 ,

2

8 ,

$2 "$

1 ,

31 yenrs.

10 hours.

4 days.

33 hours.

$\left.\begin{array}{l}4 \\ 1\end{array}\right\} \quad 5$

5) 6

9 cases.

1 "

1 "

1 ,

5,

1 ,

4

1,

1

31 years.

7 hours.

51 ,

23 ",

$3) \quad 4$

$2\}$

1 case
The case of concealed hæmorrhage in which perforation was performed, and death followed, has been named elsewhere. In one forceps case intense intestinal irritation followed, from impacted cherry-stones. The patient ultimately did well. All the rest recovered without any unfavourable symptoms. There was no case of injury to the soft parts; nor lacerated perinæum.

Induced Labour.-Two cases.

In one case labour was induced at seven months, on account of a tumour. The feet and cord presented. The child lived a short time. Labour was another time brought on at eight months in the same patient. The breech presented. The child died in the birth from want of assistance. The mother did well.

It will be remarked that the ages of both classes of cases are somewhat advanced, bearing a mean of thirty-one years in the forceps, and thirty-five years in the perforator cases; that of the eighteen cases, twelve (two-thirds) were in first pregnancies; that the mean duration of the forceps cases was thirtythree hours; of the perforator, twenty-three hours; that the children in all the forceps cases (alive at the labour) were preserved; that the forceps was used twice when the children were dead ; that the perforator was used in five living and two dead children; and that the after illness was limited to a solitary case of intestinal irritation.

The influence of age must be passed over now. That twothirds of the cases were first pregnancies, is a circumstance to be specially noted. The consideration, however, of this subject, involving as it does one of the most interesting inquiries in obstetrics-viz., the preparatory treatment of pregnancy-is much too important to be cursorily considered, and must be put off to a more convenient season.

The mean duration of the forceps cases was thirty-three hours; of the perforator, twenty-three; and of the lingering, thirty-three hours. You will not have failed to remark that there is a great range of duration; in the lingering, from twenty-five to fifty-eight hours ; in the forceps cases, from ten hours to four days; in the perforator cases, from seven to fifty-one hours; the latter having the shortest time, the most limited range, and the smallest mean. There appears to have been no fixed rule followed here. In one case, perforation was performed in seven hours; and in another, I waited four days before the forceps was applied. A principle, however, was obeyed, one immutable in surgery; viz., not to interfere before it is necessary, but when necessary, without delay, to interfere. As before stated, a lingering labour of fifty-eight hours may be perfectly natural; while in another case, it may be needful to perforate in seven hours.

I hold that it is opposed to all sound experience to attempt to lay down any absolute rule, to teach that the forceps shall be applied only after a long ineffectual struggle, and the perforator only after so many hours more, when utterly exhausted, as a dernier ressort. I hold that a comprehensive survey of the condition of the patient will show and does show the time when to interfere. This condition is curtly comprised in two words, "done up"; words as expressive of a state as its definition is difficult.

As regards the preference of craniotomy to the forceps, my rule has been this. When I could not get at the head with these forceps (Ramsbotham's), then I use the perforator. I do not mean to say that in some favourable cases, a dexterous operator might not seize the head when far above the brim with a long forceps; but such cases, suitable or successful, are the exception, not the rule. 
It is laid down in books, as a fundamental precept, that the perforator, not the forceps, should be resorted to for the delivery of dead children. The reason assigned is, that the perforator is a safer instrument than the forceps. I beg to doubt the correctness of the supposition and the propriety of the practice. In a case of twins (before named), I perforated the first child, because I could not; and I did not use the perforator to the second, because I could get at it with the forceps.

When the necessity for the use of the perforator is in my mind clearly established, I have not hesitated, holding paramount the safety of the mother, to employ it, irrespectively of the child being dead or alive.

A very laudable desire has been expressed by Dr. Tyler Smith, on the desirability of abolishing the operation of craniotomy. It would be well indeed could this be accomplished but, bearing in mind that the difficulties usually arise in first children, where previously we have had no means of ascertaining the exact condition of things, it is more desirable than possible. After the first labour, when the difficulty has been discovered, then it would not only be culpable, but criminal, to neglect, as the chief means of averting so dire a necessity, the induction of premature labour. This was done twice in the same patient, when at the first labour a tumour was discovered. It is well for the interests of humanity that the dangerous facility with which this operation can be effected, is unknown-if it is unknown; and, if not unnamed, not fully described in ordinary channels. The manifold uses of warm water are not yet enumerated. Of its appliance and value in natural labour, I hope fully to speak at no distant period.

[To be continued.]

\section{THE PATHOLOGY, DIAGNOSIS, AND TREATMEN'T OF CARDIAC DISEASES.}

By W. O. Markhay, M.D., F.R.C.P., Physician to St. Mary's Hospital, London.

VI.-Treatient of Pericarditis. General Remarks Bleeding; Mercury ; Opium; Generar and Local Treatmext; Paracentesis of the Pericardiuar PeriCARDIAI ADHESTONS.

IN considering the treatment of pericarditis, it is necessary to bear in min i a fact already referred to, namely, that pericarditis (excepting in the case where it is the consequence of traumatic injury) is not an idiopathic inflammation; that is, not idiopathic in the sense in which we use the term, as applied, for instance, to ordinary inflammation of the lungs.* Pericarditis, when not of traumatic origin, or excited by the local action of tumours, etc. in the neighbourhood of the pericardium, is manifested either secondarily, as the result of some other disease present elsewhere in the body,- of purulent absorption for instance; or as one of the local expressions of some general disorder of the system, - of its fluids or its solids, - as in the case of rheumatic fever. Unless these distinctions, in the origin of the disease, be properly recognised by the practitioner, he will never arrive at a correct and rational method of treating pericarditis.

Excluding, then, from consideration those cases of pericarditis, which are the results of traumatic injuries, or other local affections, we find, that we have to deal with a disease which is connected with some particular diathesis, or constitutional disorder, not merely with a local inflammation. One treatment, therefore, must be directed to the constitutional disorder as well as to the pericardial affection. And since, as

* I say advisedly, "as usually applied to inflammation of the lungs"; for I do not wish to be here understood, as considering that so-called idionathic pneumotia is realiy and truly invariably such. I have already referred to the fact, that pathology is daily diminishing the number of those idiopathis local diseases, and referring them to some nore general and excitin cause, present in the body. There are many reasons which justify the belief that "idiofrathic pneumonia" may possibly be merely the local signs of general disor'der. We must remember, therefore, that "idiopathic" mean merely, and no more than, this ; viz., that, so far as we at present see, the inflammation is a local disorder, provoked by local causes, and having 110 relation to any particular general disorder of the system; and admitting, as we must, our very imperfect knowledge concerning the exciting causes of diseases in general, and marking, as before said, the more enlarged view which modern pathology has opened to us concerning their nature, w should at least be cantious in localising the disease in the existing and perhaps accideutal derangements of parts. we have seen, pericarditis is associated with many different constitutional disorders, it is manifest that no general directions of treatment can be prescribed, which shall be adapted to every case; for each case demands a particular consideration-a consideration founded, in the first place, upon the nature of the exciting cause, or upon the relation of the pericarditis to the constitutional affection; and secondly, upon the age, constitution, and condition in life of the patient. These are the data upon which a rational treatment must be founded.

It follows necessarily from this, that the treatment which may be proper in one case, is most unfitted for another case and, therefore, that in different cases, different plans and methods of treatment become the true and proper methods.

We have already seen, when describing the causes of pericarditis, that it was necessary to divide the disease into two general classes, rheumatic and non-rheumatic; and in accordance with what has been there advanced, I shall consider the treatment of the disease under these two separate heads.

The first sort, the rheumatic pericarditis, includes generally all the most acute forms of the disease. In such, the local inflammation itself becomes the chief centre towards which the treatment is especially directed ; for it is this local inflammation which immediately tends to the destruction of life, and in the manner I have already described. The local character of the inflammation, therefore, and the consequences resulting from it, are the characteristics of rheumatic pericarditis,-its prominent features. The same cause which brings out the pericarditis is, perchance, the cause of the arthritic affections, and may be the cause of other local inflammations; but all such other co-existing and localised affections, are of diminished im portance in comparison with the pericardial affection. Once the pericarditis has declared itself, it becomes the primary object of our treatment; the others are but secondary and subordinate oljects.

On the other hand, in the non-rheumatic form of pericarditis, the local inflammation is rarely of other than secondary im. portance; its symptoms are oftimes so little marked, so obscure, and produce, by their reaction, so little disturbance of the constitution, that the existence of the inflammation may altogether escape observation, if not carefully watched for and anticipated. Where non-rheumatic pericarditis occurs, death very generally ensues, but it is not the pericarditic inflamma. tion, which is the chief destroyer of life in such cases. Although the local inflammation is ten times more severe in the rheumatic form of pericarditis, death is an exceptional result, whilst here in the non-rheumatic form it is the rule; and when we seek a clue to elucidate this apparent discrepancy, we find it at once in the different nature of the maladies with which the inflammations are associated. Acute rheumatism is not, per $s e, \mathbf{a}$ fatal malady : but uræmia is, and so are very generally those forms of erysipelas, of tuberculosis, of scarlatina, of typhus, of pyæmia, of pneumonia, of pleurisy, in the course of which non-rheumatic pericarditis appears, and which are erroneously said to be its causes.

Speaking generally, then, and in accordance with the foregoing remarks, I may say: That the treatment of the nonrheumatic form of pericarditis is the treatment of that particular general affection, with which it happens to be associated; and that the treatment, therefore, has quite a secondary reference to the particular local inflammation. Such is the rule; but of course it has its exceptions: for we now and then, though very rarely, meet with cases of non.rheumatic pericarditis, in which the local inflammation takes on such a form as to become a very prominent part of the disorder.

On the other hand, in the case of rheumatic pericarditis, we have to treat both the general disorder and the local inflammation. The diathetic rature of the disease indicates, that the general treatment should be mainly the treatment of acute rheumatism. And the local inflammation demands the use of local remedies; its peculiar seat,-its immediate relation to the heart-indicating, besides, some special objects for our consideration in this respect. It is to the acute inflammation, therefore, as we find it especially typified in rheumatic pericarditis, that the following remarks on its treatment apply.

Blceding, in the treatment of pericarditis, has been very highly extolled; at the present moment, however, its practice is generally abandoned in this country. That its value, as a remedial agent, has been overstated by Boulllaud and many other admirers of the practice, is now universally admitted.

"Contrast," says Dr. Benuett, " the treatment of Hope with that of Stokes, and what a difference is observalle! The former energetic in lowering remedies, the latter cautious, and constantly warning us not to proceed too far. Though he 889 